\title{
Hemosuccus Pancreaticus in a Child - A Case Report
}

\author{
Vijayalakshmi Ambati ${ }^{1}$, Sreelekha Palle², Prathyusha Peddolla ${ }^{3}$ \\ 1, 2, 3 Department of Paediatrics, Niloufer Hospital, Osmania Medical College, Hyderabad, Telangana, India.
}

\section{INTRODUCTION}

Pleural effusions in acute pancreatitis are usually small, occasionally bloody, characterized by high amylase, protein levels. ${ }^{1}$ Majority of pleural effusions secondary to pancreatitis are left-sided (68\%) or bilateral (22\%) and only $10 \%$ are right sided. Hemosuccus pancreaticus (HP) is caused by rupture of aneurysm of a peripancreatic vessel into pancreatic duct or pancreatic pseudocyst in the context of pancreatitis. HP is the least frequent cause of upper gastrointestinal bleeding (1 / 1500 ), but can lead to potentially life threatening2 massive gastrointestinal bleeding.

Hemosuccus pancreaticus is defined as bleeding from the ampulla of Vater via pancreatic duct. It is due to a bleeding source in the pancreas, pancreatic duct, or structures adjacent to the pancreas, like the gastroduodenal and splenic artery. The most common cause is a pseudoaneurysm of peripancreatic arteries due to acute or chronic pancreatitis. ${ }^{3,4}$ Other rare causes are trauma, ${ }^{5}$ rupture of a true aneurysm, ${ }^{6}$ pancreatic tumours, ${ }^{7}$ arteriovenous (AV) malformations, ${ }^{8}$ endoscopic ultrasoundguided fine needle aspiration from pancreatic cyst ${ }^{9}$ etc.

\section{PRESENTATION OF CASE}

A 3-year-old male child was brought to the emergency department of Niloufer Hospital, Hyderabad, with complaints of cough, fever and difficulty in breathing for 3 days. There were no similar complaints in the past or hospital admissions for any illness. There was no significant family medical history. The child belonged to lower socioeconomic class, living in a rural area.

At the time of admission, child had New York Heart Association (NYHA) grade-4 dyspnoea and severe palmar pallor according to Integrated Management of Neonatal and Childhood Illness (IMNCI) grading. The child was sitting, leaning forward, shoulder drooping to right side. On auscultation he had tachycardia and decreased breath sounds on right side. Chest $\mathrm{x}$-ray showed massive pleural effusion on right side [Figure 1]. Due to severe respiratory distress, therapeutic thoracocentesis was done which showed haemorrhagic fluid collection. Intercostal drain (ICD) was inserted. The child had a haemoglobin of $4 \mathrm{~g} / \mathrm{dl}$ at admission, white blood cell (WBC) count of 20,200 / mm3, platelet count of 2 lakhs $/ \mathrm{mm}^{3}$. He was given 2 packed red cell transfusions over 2 days. Coagulation profile done at admission was PT- 14.6 seconds, aPTT- 30 seconds, INR -1.3. Serum amylase and lipase were $285 \mathrm{U} / \mathrm{L}$ and $330 \mathrm{U} / \mathrm{L}$ respectively. Pleural fluid analysis showed WBC of 220 cells / $\mathrm{mm}^{3}, 88 \%$ lymphocytes, red blood cells (RBC) of 1,30,000 cells / $\mathrm{mm}^{3}$, proteins-33 g / dl, amylase $6600 \mathrm{U} / \mathrm{L}$, ADA $32 \mathrm{U} / \mathrm{L}$, culture negative for bacteria, Mycobacterium tuberculosis and malignant cells were not detected. ICD was removed after 3 days. There was a drainage of $1100 \mathrm{ml}$ of haemorrhagic pleural effusion in 3 days. There were no AV malformations on general examination. Child's anthropometry was appropriate for his age. There was no history of usage of drugs that could have caused pancreatitis. The child's parents go to field for agricultural work, leaving him at home with his 80-year-old grandmother, leaving scope for unnoticed trauma which could have caused pancreatitis. 4 weeks later, child had 3 episodes of melena and 1 episode of hematemesis.
Corresponding Author: Dr. Sreelekha Palle, H. No. 11-5-95/12NP, Jaiswal Colony, Road No. 5, Venkateshwara Colony, Saroornagar, Hyderabad-500035, Telangana, India. E-mail:drsrilekha05@gmail.com

DOI: $10.14260 /$ jemds/2022/57

How to Cite This Article: Ambati V, Palle S, Peddolla P. Hemosuccus pancreaticus in a child - a case report. J Evolution Med Dent Sci 2022;11(01):305307, DOI: 10.14260/jemds/2022/57

Submission 30-06-2021, Peer Review 07-07-2021, Acceptance 21-01-2022, Published 31-01-2022.

Copyright (C) 2022 Vijayalakshmi Ambati et al. This is an open access article distributed under Creative Commons Attribution License [Attribution 4.0 International (CC $B Y 4.0)]$ 


\section{CLINICAL DIAGNOSIS}

At the time of admission ultrasonography (USG) of abdomen showed mild ascites, bulky pancreas with surrounding fat stranding and thrombosis of portal vein. Contrast enhanced computed tomography (CECT) chest and abdomen showed moderate right pleural effusion, acute pancreatitis with peripancreatic fat stranding, portal vein thrombosis and mild to moderate ascites. Liver function test (LFT) were normal; there was no evidence of haemolysis or gallstones, no evidence of anatomical abnormalities on imaging. Autoimmune profile was negative. Lipid profile was normal. Alpha1 antitrypsin levels were normal.

4 weeks later, at the time of gastrointestinal bleed, upper gastrointestinal endoscopy (UGIE) showed no significant findings. USG abdomen showed hypoechoic collection measuring $5.8^{*} 3 \mathrm{~cm}$ in lesser sac, extending into head of pancreas, dilated pancreatic duct, and rest of the pancreas appeared atrophic. Computed tomography (CT) abdomen was repeated at this time which showed pancreatic pseudocyst measuring $5^{*} 2.8 \mathrm{~cm}$ and dilated pancreatic duct measuring $5 \mathrm{~mm}$. CT angiogram was done which showed saccular splenic artery aneurysm, variant origin of common hepatic artery from superior mesenteric artery, chronic portal vein thrombosis with recanalization. Magnetic resonance cholangiopancreatography (MRCP) showed evidence of T2 Short-Tau-Inversion-Recovery (T2STIR) increased signal intensity collection measuring $36 * 40 * 20.5 \mathrm{~mm}$ in superior recess of lesser sac, thinned out pancreatic parenchyma with dilated main pancreatic duct measuring $5 \mathrm{~mm}$, features suggestive of chronic pancreatitis with pseudocyst. Aortogram showed no evidence of aneurysm anywhere else in the aorta or its branches.

The informed written consent of the child's parents was taken.

\section{DIFFERENTIAL DIAGNOSIS}

1. Chronic pancreatitis.

2. Hemosuccus pancreaticus secondary to aneurysm.

\section{PATHOLOGICAL DISCUSSION}

Lower and Farrell first described bleeding through the pancreatic duct due to the rupture of a splenic artery in 1931.10 The term hemosuccus pancreaticus was coined by Sandblom in $1970 .{ }^{11}$ In $80 \%$ of cases, HP complicates an underlying pancreatic disease; $20 \%$ of the cases correspond to a vascular anomaly. ${ }^{12,13}$

Typical manifestations are abdominal pain and gastrointestinal bleeding. Pain is localized to epigastrium or radiates towards the back. The cause is a transient increase in intraductal pressure by a blood clot. The pain is relieved when blood leaves into the gastrointestinal tract producing melena, hematemesis or occasionally haematochezia. But in infants and toddlers who cannot express this pain in words, it is a difficult symptom to rely on. Bleeding is usually intermittent in nature of varying magnitude.
The gastroduodenal, splenic, common hepatic and pancreaticoduodenal arteries are mostly involved. ${ }^{14}$ Pancreatic duct injuries may occur secondary to acute and chronic pancreatitis. Pseudocysts contain activated lytic enzymes; elastases, in particular. These enzymes exert an elastolytic action on the vessel walls resulting in pseudoaneurysm which may rupture and cause bleeding which is intermittent owing to clot formation in the main pancreatic duct. 15
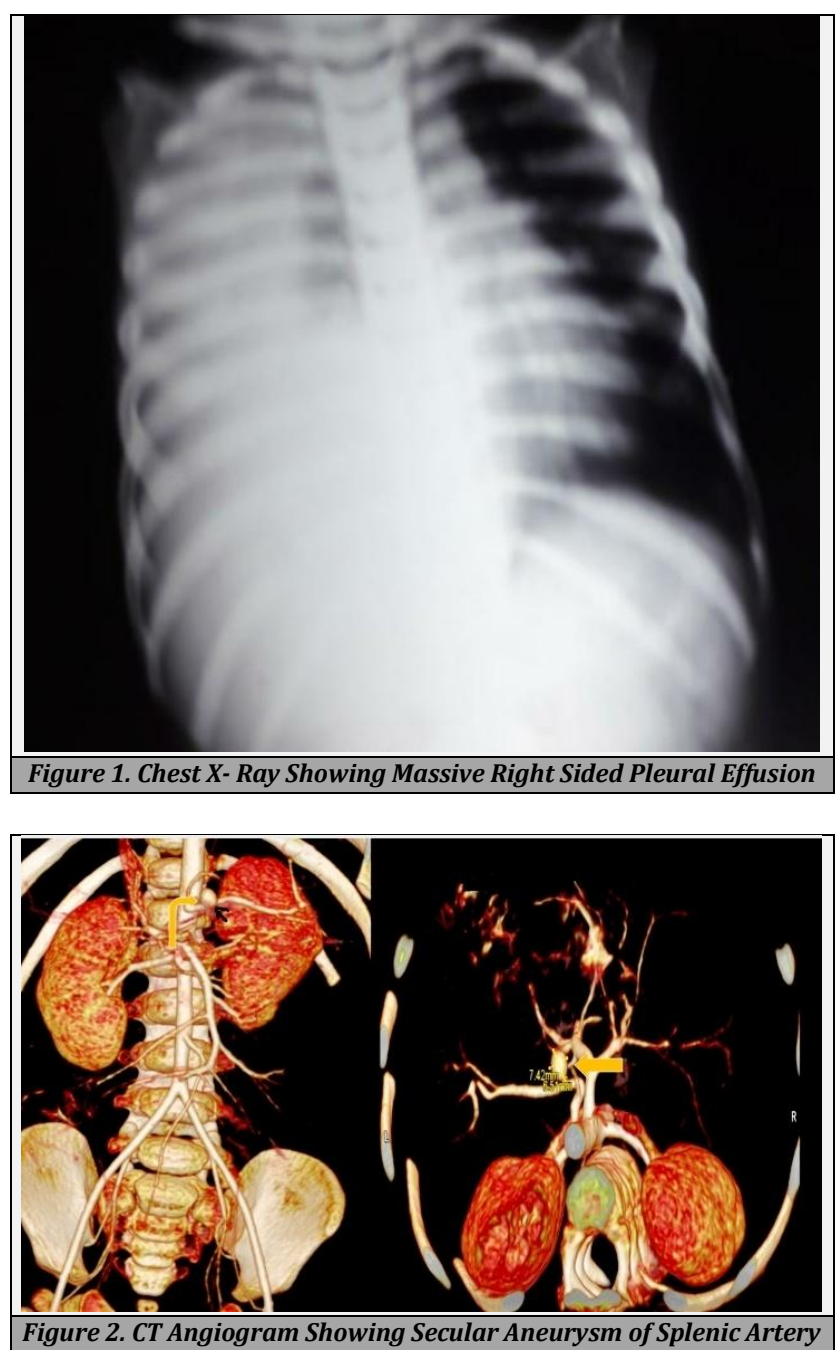

DISCUSSION OF MANAGEMENT

At admission, the child was on supportive management for acute pancreatitis. ICD was put for 3 days to drain the haemorrhagic pleural effusion. When the child developed splenic artery aneurysm and hemosuccus pancreaticus, surgery was deferred by the Department of Paediatric Surgery due to subacute nature of the condition, non-recurrence of bleeding, young age of the child and spontaneous regression on follow up imaging. The child was under follow up and the aneurysm has spontaneously resolved by 6 months. Repeat CT and USG, done at 6 months interval twice, showed no evidence of splenic artery aneurysm or portal vein thrombus.

Management of hemosuccus pancreaticus varies according to the case. The first step is assessment of severity of blood loss, resuscitation and appropriate monitoring. The next step is localization of the source of the bleeding. Upper 
gastrointestinal endoscopy can visualize active bleeding via the papilla in $30 \%$ of patients, causing suspicion of HP. ${ }^{13}$ CECT is a good method for demonstrating pancreatic pathologies. Visceral angiography is the most sensitive test for a visceral artery aneurysm or pseudoaneurysm with sensitivity approaching $96 \% .^{5}$ In our case, the CT angiography showed splenic artery aneurysm.

Therapeutic options are supportive management, surgery and angioembolization; offered based on the clinical status, size of aneurysm and its impact on surrounding structures. Angio-embolization is safe and effective for immediate haemostasis, with a success rate of 80 to $100 \%$. Recurrent bleeding may occur in $17-37 \%$ cases $^{16}$ following embolization, which can be managed by surgery or by repeat embolization. Mortality from surgical intervention ranges from 20 to $25 \%$. Rebleeding rates are significantly lower $(0-$ $5 \%)$ than that of embolization. ${ }^{17,18}$ The present case underwent spontaneous resolution unlike prior reported cases.

\section{FINAL DIAGNOSIS}

The child was diagnosed with acute pancreatitis, complicated by haemorrhagic pleural effusion on the right side, at the time of presentation. 4 weeks later, owing to the intermittent nature of the child's upper GI bleeding and lack of findings on upper GI endoscopy and the presence of pancreatic pseudocyst and aneurysm of saccular artery, we have come to a conclusion that the child has HP. Consent of the parents has been taken for the case report.

The diagnosis of HP requires a high level of suspicion. It can cause a diagnostic and therapeutic dilemma due to the fact that bleeding into duodenum is intermittent and cannot be easily diagnosed by endoscopy. It should be considered in all upper gastrointestinal bleeding in patients with a history of pancreatitis.

Due to its infrequency and insufficient epidemiological data limited to few case reports and a few case series, ${ }^{6-9}$ diagnosis is often delayed or missed.

Unlike, in most prior reported cases of HP where gastroduodenal artery was the bleeding source which required surgical intervention or embolization, in the present case splenic artery aneurysm is identified as a cause of HP with spontaneous resolution of aneurysm.

Financial or other competing interests: None.

Disclosure forms provided by the authors are available with the full text of this article at jemds.com.

\section{REFERENCES}

[1] Basran GS, Ramasubramanian R, Verma R. Intrathoracic complications of acute pancreatitis. $\mathrm{Br} J$ Dis Chest 1987;81(4):326-31.
[2] Yu P, Gong J. Hemosuccus pancreaticus: a mini-review. Ann Med Surg 2018;28:45-8.

[3] Cahow CE, Gusberg RJ, Gottlieb LJ. Gastrointestinal hemorrhage from pseudoaneurysms in pancreatic pseudocysts. Am J Surg 1983;145(4):534-41.

[4] Maus TP. Pseudoaneurysm haemorrhage as a complication of pancreatitis. Mayo Clin Proc 1993;68(9):895-6.

[5] Kim SS, Roberts RR, Nagy KK, et al. Hemosuccus pancreaticus after penetrating trauma to the abdomen. J Trauma 2000;49(5):948-50

[6] Etienne S, Pessaux P, Tuech JJ, et al. Hemosuccus pancreaticus: a rare cause of gastrointestinal bleeding. Gastroenterol Clin Biol 2005;29(3):237-42.

[7] Shinzeki M, Hori Y, Fujino Y, et al. Mucinous cystic neoplasm of the pancreas presenting with hemosuccus pancreaticus: report of a case. Surg Today 2010;40(5):470-3.

[8] Williams DM, Shetzline MA, Guarisco SA, et al. Presumed arteriovenous malformation mimicking hemosuccus pancreaticus of Santorini's duct with normal pancreatic anatomy. Gastrointest Endosc 1996;44(3):348-50.

[9] Cheruvattath R, Diehl DL. Hemosuccus pancreaticus after EUS-FNA of a pancreatic tail cyst. Gastrointest Endosc 2009;70(4):817.

[10] Lower WE, Farrel JJ. Aneurism of the splenic artery. Report of a case and review of the literature. Arch Surg 1931;23(2):182-90.

[11] Sandblom P. Gastrointestinal hemorrhage through the pancreatic duct. Ann Surg 1970;171(1):61-6.

[12] Lermite E, Regenet N, Tuech JJ, et al. Diagnosis and treatment of hemosuccus pancreaticus: development of endovascular management. Pancreas 2007;34(2):229-32.

[13] Péroux JL, Arput JP, Saint-Paul MC, et al. Wirsungorrhagia complicating chronic pancreatitis associated with a neuroendocrine tumor of the pancreas. Gastroenterol Clin Biol 1994;18(12):1142-5.

[14] Ferreira J, Tavares AB, Costa E, et al. Hemosuccus pancreaticus: a rare complication of chronic pancreatitis. BMJ Case Rep 2015;2015:bcr2015209872.

[15] Zuchelli T, Alsheik E, Bhandari B, et al. A unique case of hematemesis in a 17-year-old female. ACG Case Rep J 2014;1(3):151-3.

[16] Boudghène F, L'Herminé C, Bigot JM. Arterial complications of pancreatitis: diagnostic and therapeutic aspects in 104 cases. J VascInterv Radiol 1993;4(4):5518.

[17] Bender JS, Bouwman DL, Levison MA, et al. Pseudocysts and pseudoaneurysms: surgical strategy. Pancreas 1995;10(2):143-7.

[18] Negi SS, Sachdev AK, Bhojwani R, et al. Experience of surgical management of pseudo-aneurysms of branches of the coeliac axis in a North Indian Hospital. Trop Gastroenterology 2002;23(2):97-100. 